\title{
Dearth of data deters new institute to evaluate global health aid
}

Each year, developed nations pour billions of dollars into improving health in the developing world. But has all that money accomplished anything good?

A new institute is being touted as the one to answer that question, but skeptics say the available data on health is too scarce to yield meaningful analysis.

"We are not simply suffering from an information shortage in global health reporting," says Amir Attaran, professor of medicine and law at the University of Ottawa. "We are suffering from a data shortage."

Over the past five years, funding for developing-world health problems has increased dramatically. Rich nations spend more than $\$ 13$ billion dollars each year to improve health in their poorer neighbors.

But the dearth of monitoring means that no one has a sense of whether public health in those places is improving and, if so, who among those involved should take the credit.

"The sense of urgency around needing to tackle existing problems where people are suffering and dying tends to mean that careful metrics and evaluation get put on the back burner," says Christopher Murray, who will lead the new Institute for Health Metrics and Evaluation, housed at the University of Washington in Seattle. Murray spent several years at the World Health Organization (WHO) and as director of the Harvard Initiative for Global Health.

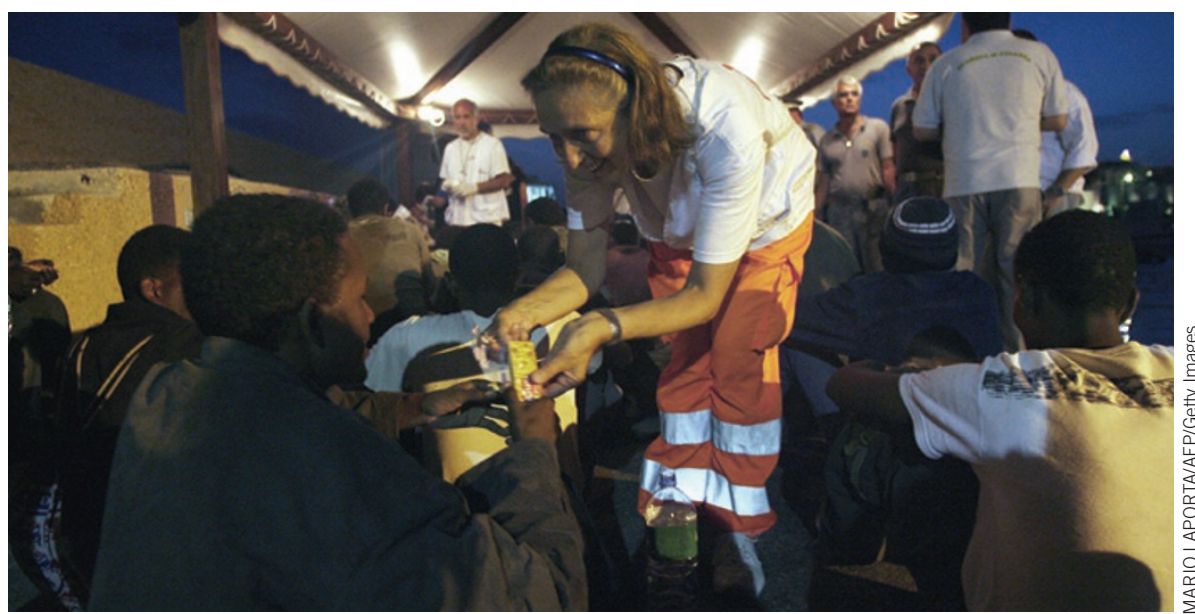

Down the drain: Is the money being poured into global health programs making a difference?

Murray says the institute will pool existing data from hospitals, surveys and censuses with new methods of analysis to create a more accurate picture of global health.

For example, data from hospitals may not accurately represent the population at large. "So the challenge in this area is to analyze these data sets in a way that takes into account the selection bias problem that is pervasive," he says.

But critics note that before the institute can analyze the numbers, it must first find them.

Only a few diseases in developing countries are tracked carefully and, in many nations, the most basic data-for example, who died and why_are not available.

a report strongly criticizing the initial proposed ban.

The debate has also raised questions about the performance of the Human Fertilisation and Embryology Authority (HFEA), which grants licenses for embryo research in the UK.

The HFEA was widely blamed for fueling the controversy over hybrid embryos by referring the cybrid applications to politicians, encouraging attacks by those who want to see such work outlawed on religious grounds.

Advocates of hybrid embryo research fear that, because it attempts to mark out the playing field so strictly, the bill will cause future applications for new techniques to encounter similar difficulties.

"Someone will have an idea about why
Attaran argues that surveillance centers established throughout the developing world should collect numbers on public health. "Once we get good data, then we can start doing some analyses in Seattle and elsewhere," he says.

Others say that the WHO would have been better suited for the institute's task because it has more authority to ask countries for data.

But the WHO is too actively engaged in raising funds for and implementing its own programs to be an unbiased critic, says Murray. "It's never a wise idea to have the same group advocate for money, provide technical assistance and implement programs - and then turn around and evaluate [its] own work," Murray says.

The new institute, funded by a \$105 million grant from the Bill \& Melinda Gates Foundation and \$20 million from the University of Washington, also aims to evaluate the impact of global health initiatives on developing countries.

Until now, says Roger Bate, an economist at the American Enterprise Institute for Public Policy Research in Washington, DC, the effectiveness of these programs has too often been gauged by how much money is invested, rather than by the results.

"It would be like measuring the success of a movie by its cost of production rather than its box office receipts," Bate says.

Closer scrutiny and oversight might improve the effectiveness of these initiatives. "Shoddy performers are going to have to try to hide the fact that they're failing," Bate adds, "or change."

The institute's first task is a review of childhood mortality since 1970 in every country, scheduled for release in the fall.

Cassandra Willyard, New York 